\title{
A survey of user acceptance of electronic patient anesthesia records
}

\author{
Hyun Seung Jin, Myung Hee Kim, Suk Young Lee, Hui Yeon Jeong, Soo Joo Choi, and Hye Won Lee
}

Department of Anesthesiology and Pain Medicine, Samsung Medical Center, Sungkyunkwan University School of Medicine, Seoul, Korea

Background: An anesthesia information management system (AIMS), although not widely used in Korea, will eventually replace handwritten records. This hospital began using AIMS in April 2010. The purpose of this study was to evaluate users' attitudes concerning AIMS and to compare them with manual documentation in the operating room (OR).

Methods: A structured questionnaire focused on satisfaction with electronic anesthetic records and comparison with handwritten anesthesia records was administered to anesthesiologists, trainees, and nurses during February 2011 and the responses were collected anonymously during March 2011.

Results: A total of 28 anesthesiologists, 27 trainees, and 47 nurses responded to this survey. Most participants involved in this survey were satisfied with AIMS (96.3\%, 82.2\%, and $89.3 \%$ of trainees, anesthesiologists, and nurses, respectively) and preferred AIMS over handwritten anesthesia records in $96.3 \%, 71.4 \%$, and $97.9 \%$ of trainees, anesthesiologists, and nurses, respectively. However, there were also criticisms of AIMS related to user-discomfort during short, simple or emergency surgeries, doubtful legal status, and inconvenient placement of the system.

Conclusions: Overall, most of the anesthetic practitioners in this hospital quickly accepted and prefer AIMS over the handwritten anesthetic records in the OR. (Korean J Anesthesiol 2012; 62: 350-357)

Key Words: Electronic anesthesia records, Handwritten anesthesia records, User acceptance.

Received: May 27, 2011. Revised: 1st, July 1, 2011; 2nd, July 27, 2011. Accepted: July 31, 2011.

Corresponding author: Myung Hee Kim, M.D., Ph.D., Department of Anesthesiology and Pain Medicine, Samsung Medical Center, Sungkyunkwan University School of Medicine, 50, Ilwon-dong, Gangnam-gu, Seoul 135-710, Korea. Tel: 82-2-3410-2470, Fax: 82-2-3410-0361, E-mail: myungsmc@yahoo.co.kr

(c) This is an open-access article distributed under the terms of the Creative Commons Attribution Non-Commercial License (http:// creativecommons.org/licenses/by-nc/3.0/), which permits unrestricted non-commercial use, distribution, and reproduction in any medium, provided the original work is properly cited. 


\section{Introduction}

Along with benefits of cost savings, stability, improvement in quality of care, reduction in a patient's waiting time, and ease of access to stored patient information records and their use, hospital-wide electronic medical records (EMRs) have recently been introduced in many hospitals in Korea. The anesthetic information management system (AIMS) is currently installed in several departments of anesthesiology in Korea. The AIMS at our hospital, was implemented on April 2010, after $\sim 1$ year of development and testing, and double charting periods together with manual recording and automated recording. AIMS is now routinely used in the main and auxiliary operating theaters to record patient clinical information before anesthesia and anesthetic data perioperatively.

According to previous studies, computer generated anesthetic records provide significant benefits over handwritten records [1-13]. AIMS is easy to read, allows more accurate and effective recording of data, and more cost-effective anesthetic management. It is also useful for research, and potentially advantageous in legal issues. Nevertheless, despite the growth of internet technology and thus general familiarity towards automated information systems, as mentioned in the study conducted by AIMS by Eden et al. [2], a significant percentage of the anesthetic community may have less experience with computers, which may cause some degree of fear and resistance in proper adaptation and making good use of AIMS. Moreover, being uncomfortable with new technology may create new problems with the anesthetist machine interface, and actually reduce its potential advantages [14]. No studies have been conducted regarding clinician attitudes towards, or acceptance of AIMS compared to the previous manual anesthetic documentation in operating rooms (OR) in Korea.

Therefore, the aim of this survey was to evaluate the attitudes of the attending anesthesiologists, trainees, and nurses towards automated anesthetic records, and to compare findings with the previous manual documentation methods, after 1 year routine use of AIMS at our hospital.

\section{Materials and Methods}

This study was based on a survey questionnaire concerning the opinions of anesthetic practitioners as users, towards the currently developed computerized anesthetic recording system in the OR. The survey questionnaire was distributed to eligible participants including attending anesthesiologists (A), anesthetic trainees $\left(2^{\text {nd }}-4^{\text {th }}\right.$ year residents) $(\mathrm{T})$ and nurses $(\mathrm{N})$ during Feb 2011, and the confidential responses were collected anonymously during March 2011 (Table 1). The transition of the practice year in Korea is every first day of March. Because our study was conducted in this transition period (from February to March), the pre-1st year residents (who actually became 1st years starting from March 2011) were excluded due to their inexperience with the system.

Before the installation of AIMS, all anesthetic records were handwritten. The AIMS at our hospital was implemented during April 2010, after $\sim 1$ year of development. Beginning in February 2010, a test period of 1 month, and a double charting with manual documentation for another month were implemented, during which program improvement through modifications was conducted. During the month just before the test period, a total of 5 repeated sessions (60-120 min each session) was provided to all staff anesthesiologists, trainees, and nurses. Newly recruited nurses were given orientation sessions on the use of AIMS, and a 1- month observation and practice period. The shortest period of AIMS experience of the respondents was 2 months.

More than 40,000 anesthetic procedures are annually performed at several locations of this hospital including the main operation center, cancer operation center, outpatient operation center, labor and delivery center, cardiovascular angiography center, angiography center, and endoscopic center. Since its successful implementation, AIMS has been routinely used to record anesthetic data, intervention procedures and treatments at all workstations except for the cardiovascular angiography center, labor and delivery floor, and angiography center, where anesthetic data are still recorded manually.

Computerized anesthetic documentation is carried out by an anesthetic trainee or nurse under the auspice of an attending anesthesiologist. Because anesthetic trainees and nurses rotate through all working centers, one could assume that all respondents to the current survey were familiar with AIMS. The hardware system of AIMS, such as the display screen monitor, mouse, and keyboard are all mounted on an articulated arm affixed to the wall or ceiling at the bedside

Table 1. Characteristics of the Respondents

\begin{tabular}{lcc}
\hline & $\begin{array}{c}\text { Anesthesiologists } \\
(\mathrm{n}=55)\end{array}$ & $\begin{array}{c}\text { Nurses } \\
(\mathrm{n}=47)\end{array}$ \\
\hline Position & & \\
$\quad$ Resident anesthesiologists & 27 & \\
$\quad$ Attending anesthesiologists & 28 & 47 \\
$\quad$ Nurses & 60 & 100 \\
Gender (\% female) & $1-17 \mathrm{yr}$ & $2 \mathrm{~m}-6 \mathrm{yr}$ \\
Number of years in practice & & $2 \mathrm{~m}-1 \mathrm{yr}$ \\
at this hospital & $1 \mathrm{yr}$ & $0 \mathrm{~m}-5 \mathrm{yr}$ \\
Duration of EMR use in OR & & \\
$\begin{array}{l}\text { Duration of handwritten } \\
\text { record use in OR }\end{array}$ & & \\
\hline
\end{tabular}

EMR: electronic medical record. OR: operating room. m: months, yr: years. 
of the operating table. AIMS is connected to other hospital EMR systems such as the patient's outpatient or admission EMR, and receives imported administrative and laboratory data. The results of blood tests conducted during anesthesia are immediately stored in the patient's scan results window. The patient monitor automatically sends vital signs such as
BP, HR, peripheral oxygen saturation, and ventilation status to the data base server (DBS) in constant intervals (vital signs normally in 5 min intervals, but in 1 min intervals in case of cardiopulmonary resuscitation (CPR), and ventilation status in $30 \mathrm{~min}$ intervals). The numbers are then sent to the hospital acquisition server (HAS) and can be reviewed through the

Table 2. Survey Results for Satisfaction Degree of the AIMS (A), and Comparison to Handwritten Recording System (B) among the Groups

\begin{tabular}{|c|c|c|c|c|c|c|}
\hline A. Satisfaction degree on AIMS, n (\%) & & 1 & 2 & 3 & 4 & 5 \\
\hline \multirow[t]{3}{*}{ User- friendly } & $\mathrm{T}$ & 0 & 0 & $2(7.4)$ & $16(59.3)$ & $9(33.3)$ \\
\hline & A & 0 & 0 & $4(14.3)$ & $14(50.0)$ & $10(35.7)$ \\
\hline & $\mathrm{N}$ & 0 & 0 & $1(2.1)$ & 30 (63.8) & $16(34.0)$ \\
\hline \multirow{3}{*}{$\begin{array}{l}\text { Meets the general needs of the record } \\
\text { keeper }\end{array}$} & $\mathrm{T}$ & 0 & 0 & $2(7.4)$ & $19(70.4)$ & $6(22.2)$ \\
\hline & A & 0 & 0 & $5(17.9)$ & $16(57.1)$ & $7(25.0)$ \\
\hline & $\mathrm{N}$ & & & NA & & \\
\hline \multirow[t]{3}{*}{ Time-saving record-keeping system $*,+$} & $\mathrm{T}$ & 0 & 0 & 0 & $15(55.6)$ & $12(44.5)$ \\
\hline & A & 0 & $4(14.3)$ & $4(14.3)$ & $9(32.1)$ & $11(39.3)$ \\
\hline & $\mathrm{N}$ & 0 & 0 & 0 & $22(46.8)$ & $25(53.2)$ \\
\hline \multirow{3}{*}{$\begin{array}{l}\text { Results in accurate recording of vital } \\
\text { signs }\end{array}$} & $\mathrm{T}$ & 0 & 0 & $3(11.1)$ & $14(51.9)$ & $10(37.0)$ \\
\hline & A & 0 & 0 & $4(14.3)$ & $8(28.6)$ & $16(57.1)$ \\
\hline & $\mathrm{N}$ & 0 & 0 & $9(19.1)$ & $23(48.9)$ & $15(31.9)$ \\
\hline \multirow{3}{*}{$\begin{array}{l}\text { Results in accurate documentation of } \\
\text { procedures and events }\end{array}$} & $\mathrm{T}$ & 0 & 0 & 8 (29.6) & $12(44.5)$ & $7(25.9)$ \\
\hline & A & 0 & $2(7.1)$ & $6(21.4)$ & $10(35.7)$ & $10(35.7)$ \\
\hline & $\mathrm{N}$ & & & NA & & \\
\hline \multirow{3}{*}{$\begin{array}{l}\text { Allows more time to concentrate on } \\
\text { patient care }\end{array}$} & $\mathrm{T}$ & 0 & $2(7.4)$ & $8(29.6)$ & $15(55.6)$ & $2(7.4)$ \\
\hline & A & 0 & $1(3.6)$ & $9(32.1)$ & $11(39.3)$ & $7(25.0)$ \\
\hline & $\mathrm{N}$ & 0 & 0 & $12(25.5)$ & $23(48.9)$ & $12(25.5)$ \\
\hline \multirow[t]{3}{*}{ Convenient in short cases } & $\mathrm{T}$ & $1(3.7)$ & $10(37.0)$ & $6(22.2)$ & $7(25.9)$ & $3(11.1)$ \\
\hline & A & $1(3.6)$ & $4(14.3)$ & $10(35.7)$ & $8(28.6)$ & $5(17.9)$ \\
\hline & $\mathrm{N}$ & $1(2.1)$ & $5(10.6)$ & $16(34.0)$ & $19(40.4)$ & $6(12.8)$ \\
\hline \multirow[t]{3}{*}{ Convenient in lengthy cases } & $\mathrm{T}$ & 0 & 0 & 0 & $9(33.3)$ & $18(66.7)$ \\
\hline & A & 0 & $1(3.6)$ & $4(14.3)$ & $13(46.4)$ & $10(35.7)$ \\
\hline & $\mathrm{N}$ & 0 & $1(2.1)$ & $4(8.5)$ & $21(44.7)$ & $21(44.7)$ \\
\hline \multirow[t]{3}{*}{ Convenient in simple cases } & $\mathrm{T}$ & 0 & $5(18.5)$ & $8(29.6)$ & $11(40.7)$ & $3(11.1)$ \\
\hline & A & $1(3.6)$ & $2(7.1)$ & $10(35.7)$ & $10(35.7)$ & $5(17.9)$ \\
\hline & $\mathrm{N}$ & 0 & $3(6.4)$ & $13(27.7)$ & $22(46.8)$ & $9(19.1)$ \\
\hline \multirow[t]{3}{*}{ Convenient in complicated cases } & $\mathrm{T}$ & 0 & $1(3.7)$ & $4(14.8)$ & $14(51.9)$ & $8(29.6)$ \\
\hline & A & 0 & $2(7.1)$ & $8(28.6)$ & $11(39.3)$ & $7(25.0)$ \\
\hline & $\mathrm{N}$ & 0 & $2(4.3)$ & $11(23.4)$ & $23(48.9)$ & $11(23.4)$ \\
\hline \multirow{3}{*}{$\begin{array}{l}\text { Beneficial in major trauma or } \\
\text { emergency cases }\end{array}$} & $\mathrm{T}$ & 0 & $2(7.4)$ & $8(29.6)$ & $12(44.5)$ & $5(18.5)$ \\
\hline & A & 0 & $3(10.7)$ & $8(28.6)$ & $8(28.6)$ & $9(32.1)$ \\
\hline & $\mathrm{N}$ & & & NA & & \\
\hline \multirow{3}{*}{$\begin{array}{l}\text { No such inconvenience for record- } \\
\text { keeping in emergency (eg. CPR) } \\
\text { situations }\end{array}$} & $\mathrm{T}$ & 0 & $6(22.2)$ & 7 (25.9) & $11(40.7)$ & $3(11.1)$ \\
\hline & A & $1(3.6)$ & $4(14.3)$ & $8(28.6)$ & $9(32.1)$ & $6(21.4)$ \\
\hline & $\mathrm{N}$ & & & NA & & \\
\hline \multirow[t]{3}{*}{ Well-located within the workplace } & $\mathrm{T}$ & 0 & $2(7.4)$ & $9(33.3)$ & $9(33.3)$ & $7(25.9)$ \\
\hline & A & 0 & $1(3.6)$ & $7(25.0)$ & $12(42.9)$ & $8(28.6)$ \\
\hline & $\mathrm{N}$ & 0 & $2(4.3)$ & $9(19.1)$ & $29(61.7)$ & $7(14.9)$ \\
\hline \multirow{3}{*}{$\begin{array}{l}\text { Easy to review the record during and } \\
\text { after the case }\end{array}$} & $\mathrm{T}$ & 0 & $4(14.8)$ & $1(3.7)$ & $10(37.0)$ & $12(44.5)$ \\
\hline & A & 0 & $1(3.6)$ & $3(10.7)$ & $7(25.0)$ & $17(60.7)$ \\
\hline & $\mathrm{N}$ & 0 & $2(4.3)$ & $8(17.0)$ & $22(46.8)$ & $15(31.9)$ \\
\hline \multirow{3}{*}{$\begin{array}{l}\text { Convenient for data collection and } \\
\text { research use }\end{array}$} & $\mathrm{T}$ & 0 & $2(7.4)$ & $4(14.8)$ & $13(48.1)$ & $8(29.6)$ \\
\hline & A & 0 & 0 & $3(10.7)$ & $8(28.6)$ & $17(60.7)$ \\
\hline & $\mathrm{N}$ & & & NA & & \\
\hline \multirow[t]{3}{*}{ I am overall satisfied with the AIMS } & $\mathrm{T}$ & 0 & 0 & $1(3.7)$ & $16(59.3)$ & $10(37.0)$ \\
\hline & A & 0 & 0 & $5(17.9)$ & $12(42.9)$ & $11(39.3)$ \\
\hline & $\mathrm{N}$ & 0 & 0 & $5(10.6)$ & $26(55.3)$ & $16(34.0)$ \\
\hline
\end{tabular}

The values are numbers (\%) of respondents. Score 1, 2, 3, 4, and 5 indicate strongly disagree, disagree, neutral, agree, and strongly agree, respectively. T, A, and $\mathrm{N}$ indicate trainees, attending anesthesiologists, and nurses, respectively. NA: not applicable. ${ }^{*,+}, \neq$ The difference between $\mathrm{T}$ and $\mathrm{A}, \mathrm{A}$ and $\mathrm{N}$, and $\mathrm{T}$ and $\mathrm{N}$, respectively, was significant $(\mathrm{P}<0.05)$. 
OR terminal personal computer (PC) monitor. The figures displayed at preset time intervals do not represent the mean value during the interval, but the latest point values measured, which can be misleading in cases of acute change in vital signs, or display false measurements. To reduce these risks, the values can be changed manually, and every change made in the data is saved in the HAS to be called out in malpractice litigations with the permission of authorized personnel. Most of the frequently used anesthetic procedures and drugs are saved as prewritten notes and set menus, respectively in hierarchical categories, and additional manual administration of adverse events or certain drugs through alphabetic search is available on the electronic anesthetic documentation. In addition, the system is supplemented with manual data entry in cases of adverse events or administration of particular drugs that are not contained in the connected order communication system (OCS).

Table 2. Survey Results for Satisfaction Degree of the AIMS (A), and Comparison to Handwritten Recording System (B) among the Groups

\begin{tabular}{|c|c|c|c|c|}
\hline B. AIMS vs. handwritten recordings, $\mathrm{n}(\%)$ & & AIMS & Handwritten & Equal \\
\hline \multirow[t]{3}{*}{ More time-saving record-keeping system ${ }^{\dagger}$} & $\mathrm{T}$ & $25(92.6)$ & 0 & $2(7.4)$ \\
\hline & A & $22(78.6)$ & $5(17.9)$ & $1(3.6)$ \\
\hline & $\mathrm{N}$ & 44 (93.6) & 0 & $3(6.4)$ \\
\hline \multirow[t]{3}{*}{ Better suited for anesthetic working performance ${ }^{\dagger}$} & $\mathrm{T}$ & $24(88.9)$ & $1(3.7)$ & $2(7.4)$ \\
\hline & $\mathrm{A}$ & $21(75.0)$ & $5(17.9)$ & $2(7.1)$ \\
\hline & $\mathrm{N}$ & $46(97.9)$ & 0 & $1(2.1)$ \\
\hline \multirow{3}{*}{ Better results in accurate recording of vital signs } & $\mathrm{T}$ & $24(88.9)$ & $2(7.4)$ & $1(3.7)$ \\
\hline & A & $26(92.9)$ & $1(3.6)$ & $1(3.6)$ \\
\hline & $\mathrm{N}$ & $45(95.7)$ & $1(2.1)$ & $1(2.1)$ \\
\hline \multirow{3}{*}{$\begin{array}{l}\text { Better results in accurate documentation of procedures } \\
\text { and events }\end{array}$} & $\mathrm{T}$ & $21(77.8)$ & $2(7.4)$ & $4(14.8)$ \\
\hline & A & $19(67.9)$ & $5(17.9)$ & $4(14.3)$ \\
\hline & $\mathrm{N}$ & & NA & \\
\hline \multirow[t]{3}{*}{ Allows more time to concentrate on patient care } & $\mathrm{T}$ & $21(77.8)$ & 0 & $6(22.2)$ \\
\hline & A & $20(71.4)$ & $1(3.6)$ & $7(25.0)$ \\
\hline & $\mathrm{N}$ & & NA & \\
\hline \multirow[t]{3}{*}{ More convenient in short cases ${ }^{\ddagger}$} & $\mathrm{T}$ & $10(37.0)$ & $11(40.7)$ & $6(22.2)$ \\
\hline & A & $15(53.6)$ & $7(25.0)$ & $6(21.4)$ \\
\hline & $\mathrm{N}$ & $35(74.5)$ & $8(17.0)$ & $4(8.5)$ \\
\hline \multirow[t]{3}{*}{ More convenient in lengthy cases ${ }^{\dagger}$} & $\mathrm{T}$ & $26(96.3)$ & 0 & $1(3.7)$ \\
\hline & A & $23(82.1)$ & 0 & $5(17.9)$ \\
\hline & $\mathrm{N}$ & $47(100)$ & 0 & 0 \\
\hline \multirow[t]{3}{*}{ More convenient in simple cases } & $\mathrm{T}$ & $17(63.0)$ & $6(22.2)$ & $4(14.8)$ \\
\hline & A & $18(64.3)$ & $6(21.4)$ & $4(14.3)$ \\
\hline & $\mathrm{N}$ & $39(83.0)$ & $4(8.5)$ & $4(8.5)$ \\
\hline \multirow[t]{3}{*}{ More convenient in complicated cases ${ }^{\dagger}$} & $\mathrm{T}$ & $26(96.3)$ & 0 & $1(3.7)$ \\
\hline & A & $21(75.0)$ & $4(14.3)$ & $3(10.7)$ \\
\hline & $\mathrm{N}$ & $45(95.7)$ & $2(4.3)$ & 0 \\
\hline \multirow[t]{3}{*}{ More convenient in major trauma or emergency cases } & $\mathrm{T}$ & $20(74.1)$ & $3(11.1)$ & $4(14.8)$ \\
\hline & A & $21(75.0)$ & $4(14.3)$ & $3(10.7)$ \\
\hline & $\mathrm{N}$ & & NA & \\
\hline \multirow[t]{3}{*}{ Better located within the workplace } & $\mathrm{T}$ & $15(55.6)$ & $3(11.1)$ & $9(33.3)$ \\
\hline & $\mathrm{A}$ & $17(60.7)$ & $4(14.3)$ & $7(25.0)$ \\
\hline & $\mathrm{N}$ & $35(74.5)$ & $4(8.5)$ & $8(17.0)$ \\
\hline \multirow[t]{3}{*}{ Safer to the patient } & $\mathrm{T}$ & $15(55.6)$ & $5(18.5)$ & $7(25.9)$ \\
\hline & A & $19(67.9)$ & $3(10.7)$ & $6(21.4)$ \\
\hline & $\mathrm{N}$ & & NA & \\
\hline \multirow[t]{3}{*}{ Advantageous for legal protection } & $\mathrm{T}$ & $17(63.0)$ & $1(3.7)$ & $9(33.3)$ \\
\hline & A & $14(50.0)$ & 0 & $14(50.0)$ \\
\hline & $\mathrm{N}$ & & NA & \\
\hline \multirow[t]{3}{*}{ Better suited for the general needs of the record keeper } & $\mathrm{T}$ & $21(77.8)$ & $3(11.1)$ & $3(11.1)$ \\
\hline & A & $22(78.6)$ & $1(3.6)$ & $5(17.9)$ \\
\hline & $\mathrm{N}$ & & NA & \\
\hline \multirow[t]{3}{*}{ My preferred method of record-keeping*, $\dagger$} & $\mathrm{T}$ & $26(96.3)$ & $1(3.7)$ & 0 \\
\hline & A & $20(71.4)$ & $2(7.1)$ & $6(21.4)$ \\
\hline & $\mathrm{N}$ & $46(97.9)$ & 0 & $1(2.1)$ \\
\hline
\end{tabular}

The values are numbers (\%) of respondents. Score 1, 2, 3, 4, and 5 indicate strongly disagree, disagree, neutral, agree, and strongly agree, respectively. T, A, and N indicate trainees, attending anesthesiologists, and nurses, respectively. NA: not applicable. ${ }^{*,+},{ }^{\ddagger}$ The difference between $\mathrm{T}$ and $\mathrm{A}, \mathrm{A}$ and $\mathrm{N}$, and $\mathrm{T}$ and $\mathrm{N}$, respectively, was significant $(\mathrm{P}<0.05)$. 
Table 3. Time Needed to Adapt to the AMIS

\begin{tabular}{lrrccc}
\hline & 1 & 2 & 3 & 4 & Median \\
\hline T, n (\%) & $11(40.7)$ & $14(51.9)$ & $2(7.4)$ & 0 & 0 \\
A, n (\%) & $9(32.1)$ & $11(39.3)$ & $4(14.3)$ & $3(10.7)$ & $1(3.6)$ \\
N, n (\%) & $10(21.3)$ & $26(55.3)$ & $11(23.4)$ & 0 & 0 \\
\hline
\end{tabular}

The values are numbers (\%) of respondents. T: trainees, A: attending anesthesiologists, N: nurses. $1:<1$ week, $2: 1-4$ weeks, $3: 1-2$ months, 4 : 2-6 months, F: failed to adapt.

For data security reasons, AIMS can be logged in with a password by anesthesiologists, trainees, and nurses in the department of anesthesiology. At the completion of anesthesia, anesthetic records are investigated and saved by anesthesiologists (any trainees and attending anesthesiologists), after which direct electronic billing takes place automatically, reducing clerical work. The recording is reviewed and finalized by the anesthesiologists in charge by clicking on the authentication button. Once this finalization is made, the anesthetic record can be viewed through any terminal PC monitors throughout the hospital, and saved as the patient's formal medical record. The final anesthetic record and all further modified versions made since finalization can be viewed on request to the medical record room.

Questions for this survey were developed in line with previous studies $[1,2,6,9]$. The first section of the current survey was composed of 16 questions concerning degree of satisfaction with AIMS for attending and resident anesthesiologists, and 11 questions for nurses who worked in the department of anesthesiology. Participants in this survey responded on a 5 point scale ranging from 1 to 5 indicating strongly disagree, disagree, neutral, agree, or strongly agree for the degree of satisfaction on the use of AIMS (Table 2A). In the second section of questions, the survey was focused on comparison of benefits between AIMS and a handwritten anesthetic recording system. Fifteen questions were given to attending anesthesiologists and trainees, and 9 questions to nurses in the second section. The participants were asked to choose the system that better met their needs (between AIMS and previously used handwritten anesthesia record), or if the systems were the same (Table 2B). In addition, the time required to properly use AIMS was asked in all groups (Table 3). Statistical analysis for comparison of responses among the participating groups was conducted with the Fishers exact test using SPSS (SPSS version 16, SPSS Inc., Chicago, USA). $\mathrm{P}<0.05$ was considered significant.

\section{Results}

Characteristics of the respondents are presented in Table 1. A total of 28 (85\%) attending anesthesiologists, 27 (100\%) trainees and $47(87 \%)$ nurses responded the current survey, and the mean return rate for this survey was $89 \%$. A captured display of the AIMS anesthetic recording in the OR is provided in Fig. 1.

Most participants $(96.3 \%, 82.2 \%$, and $89.3 \%$ of $\mathrm{T}, \mathrm{A}$, and $\mathrm{N}$, respectively) showed general satisfaction towards the use of AIMS in the OR. Most respondents felt that automated recording of vital signs using patient monitors was convenient (92.6\%, $85.7 \%$, and $97.8 \%$ of $\mathrm{T}, \mathrm{A}$, and $\mathrm{N}$, respectively), time-efficient (100\%, $72.4 \%$, and $100 \%$ of $\mathrm{T}, \mathrm{A}$, and $\mathrm{N}$, respectively), allowed more time to care for patients $(96.2 \%, 96.4 \%$, and $100 \%$ of T, A, and $\mathrm{N}$, respectively), and accurate $(88.9 \%, 85.7 \%$, and $80.8 \%$ of $\mathrm{T}$, $\mathrm{A}$, and $\mathrm{N}$, respectively). However, when asked in relation to the type of surgery, lower acceptance of AIMS was demonstrated for short cases which lasted $<30 \mathrm{~min}(37 \%, 46.5 \%, 53.2 \%$ of $\mathrm{T}, \mathrm{A}$ and $\mathrm{N}$, respectively) and simple surgeries which required less anesthetic concern regardless of the operation time $(51.8 \%$, $53.6 \%, 65.9 \%$ of $\mathrm{T}, \mathrm{A}$ and $\mathrm{N}$, respectively), compared to lengthy surgeries which lasted $>30 \mathrm{~min}(100 \%, 82.1 \%, 89.4 \%$ of $\mathrm{T}, \mathrm{A}$ and $\mathrm{N}$, respectively) and complicated surgeries with required extensively invasive monitoring and intervention (81.5\%, 64.3\%, $73.2 \%$ of T, A and N, respectively). Similarly, lower preferences were shown in operations for emergencies or major trauma, and only $63 \%$ of trainees and $60.7 \%$ of attending anesthesiologists said AIMS was convenient. Twenty two percent of trainees and $17.9 \%$ of attending anesthesiologists expressed discomfort with AIMS under CPR conditions. In regard to the placement of AIMS within the workplace, only $59.2 \%$ of trainees, $71.5 \%$ of attending anesthesiologists, and $76.6 \%$ of nurses thought it was conveniently placed. Most of the participants thought that AIMS was convenient for reviewing medical recordings, and most of the anesthesiologists indicated that the system was useful when utilizing research data (Table 2).

Preferences for the 2 systems are shown in the second section of Table 2 . The questionnaire categories were similar to those asked in the first section of Table 2, and the answers were consistent with the results from the first section, showing less preference for AIMS in short and simple surgeries, and in relation to the location within the workplace. In terms of patient safety, $55.6 \%$ of trainees and $67.9 \%$ of attending anesthesiologists thought AIMS was better, and in regard to malpractice litigations, AIMS was considered as being superior to handwritten records for managing malpractice risk by $50 \%$ of attending anesthesiologists and $63 \%$ of trainees. Overall, most of the participants $(96.3 \%, 71.4 \%$, and $97.9 \%$ of $\mathrm{T}, \mathrm{A}$, and $\mathrm{N}$, 


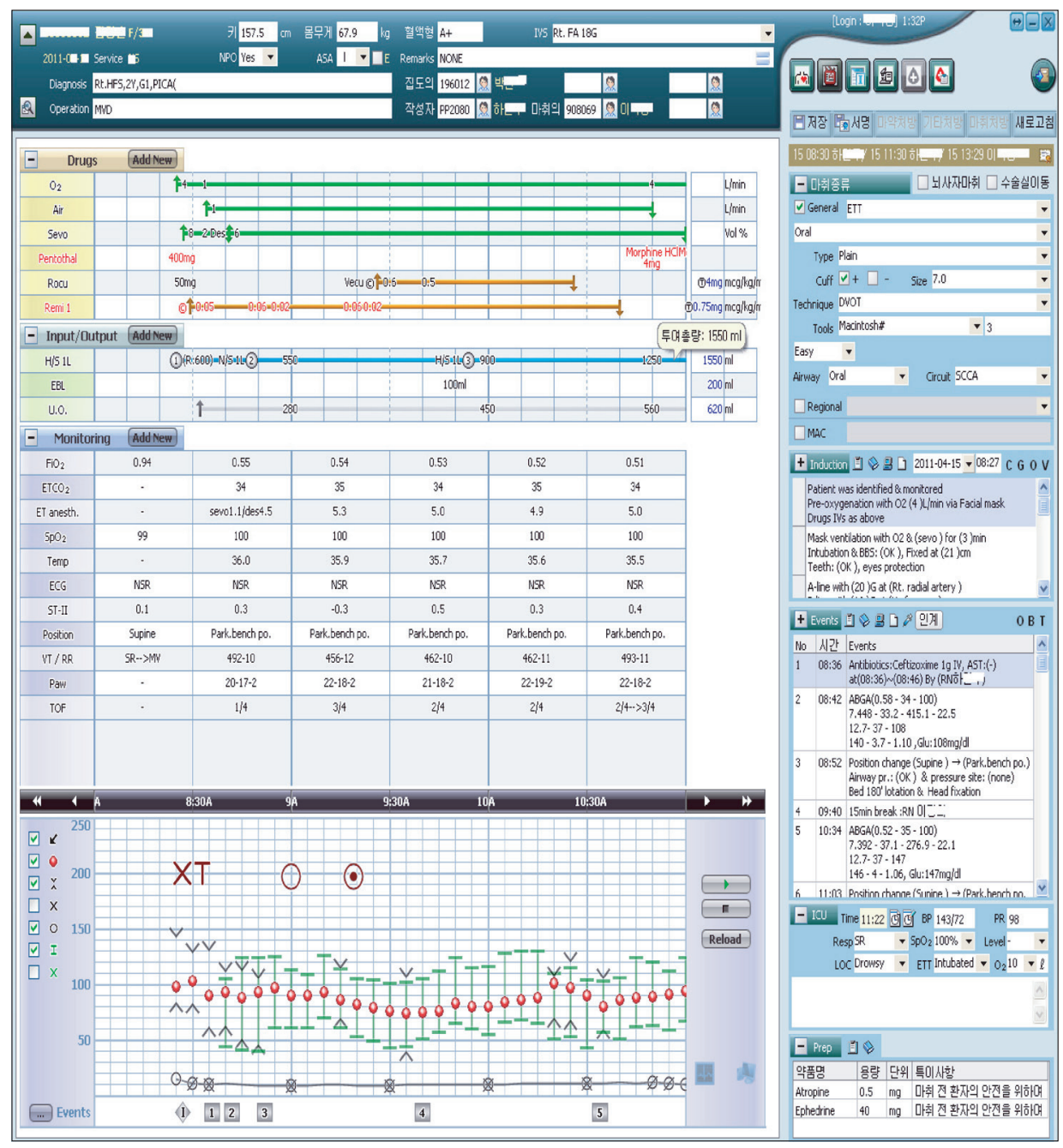

Fig. 1. A captured display of an AIMS chart. Demographic and basic patient information and type of surgery appear on the header bar. Drugs and fluids appear at the top of the main chart and followed by directly monitored data, which are displayed either in figures (checks for non invasive blood pressures (NIBPs), range bars for continuous BP, circles for HR, etc.) or tabular data (respiratory variables, temperature, ECG, etc.). Main anesthetic or surgical procedures and events are presented in a time dependent order at the right side of the display. By clicking on the time bar at the bottom of the chart, additional data can be entered manually. respectively) preferred the AIMS system. We found significant intergroup differences in some questions (Table 2). Regarding time savings, trainees, and nurses agreed on its usefulness more often than the attending anesthesiologists $(\mathrm{P}=0.023$ and $\mathrm{P}=0.002$, respectively). When considering the relation of its usefulness relative to the length or complexity of surgery, fewer trainees than the nurses $(\mathrm{P}=0.006)$ thought AIMS was better than hand-written records in short cases, while fewer attending anesthesiologists than nurses $(\mathrm{P}=0.003)$ considered AIMS superior to hand-written records in lengthy or complicated cases. When considering the suitability of AIMS for anesthetic performance, fewer attending anesthesiologists than nurses $(\mathrm{P}=0.017)$ thought it was better than the handwritten record. Overall, after 1-year routine use of AIMS, trainees and nurses groups seemed to have higher preference for the electronic anesthesia record, compared to the attending anesthesiologists, and this difference was statistically significant $(\mathrm{P}=0.002$ and $\mathrm{P}$ $=0.029$, respectively). The average time taken to use the AIMS with ease is shown in Table 3; the median of all 3 groups being
1 to 4 weeks. The trainee group showed the fastest adaptation $<1$ week in $40.7 \%$ ), but this was not statistically significant compared to the other 2 groups, respectively.

\section{Discussion}

Along with previous studies [1-13], our current survey of 1 year routine use of a computerized system revealed very positive attitudes towards EMR in anesthesia in all the medical personnel such as attending anesthesiologists, trainees, and nurses in the department of anesthesiology. Efforts to evaluate the benefits and potential problems of AIMS, and compare its usefulness in the anesthetic field with a hand-written recording system have been attempted in many hospitals of developed countries since 1989 [1-14]. Due to time requirements and the budget required to install the electronic network system for hospital medical information and anesthetic data, the implementation of AIMS in Korea was relatively delayed in the late 2000s, and currently, only a small fraction of anesthesia 
departments are using the computerized anesthetic information system.

Although there is a study that reported no advantages in adopting AIMS [14], most studies agree on its benefits and general acceptance among the anesthetic members. The advantages of AIMS are addressed in previous studies. Some of the studies specifically dealt with the aspect of user acceptance of AIMS [1,2]. Quinzio et al. reported that clinical users showed greatly positive attitudes towards a computerized anesthetic recording system after 5 years of routine use [1]. In another study, user acceptance towards new information technologies in anesthesiology was also greater after their clinical use for 6 months [2].

There is abundant evidence that AIMS is more accurate and objective in reporting a patient's hemodynamic data or adverse events, compared to manual record keeping, and reduces redundant data entry by using preexisting data from the hospital information management system $[3,4,7,10]$. The accuracy of data, along with legibility of the documents provides a good environment for research studies. By using the electronically saved database, large sized comparative or analytical studies or even multicenter data evaluation have become less troublesome [11,12]. Edsall et al. [10] suggests that computerization of record keeping saves time and improves the quality of anesthetic management. Many authors report that the use of AIMS actually improves patient care by allowing retrospective analysis of the data routinely collected for quality assurance or risk calculation, and finally providing feedback on anesthetic performance $[11,13]$. It also provides accurate economic evaluation of anesthetic drugs, thereby functioning as a cost containment tool, and is considered to have a significant potential usefulness in legal protection, in that the automated record provides complete, accurate and legible documentation to be used when defending a well-conducted anesthesia.

In this study, the questionnaire was selected to determine the subjective assessments of the participants concerning the advantages [1-13] and presumable disadvantages, such as legal issues or problems dealing with the new system, by referring to other previous studies on AIMS [5,14]. Most participants involved in this survey believed AIMS enables accurate data entry of vital signs, procedures, and events, allows more time to concentrate on patient care, provides easy access to previous anesthetic records, and easy access to patient information for later research purposes.

Positive attitudes or satisfaction for users of AIMS included the 'positive' and 'strongly positive' scores on the 5 grade scale. Overall subjective acceptance of AIMS was very high among all participants, and greatest satisfaction was observed in the trainees group: $96.3 \%$ of trainees, $82.2 \%$ of attending anesthesiologists, and $89.3 \%$ of nurses, respectively. Moreover, the overall superiority of AIMS over handwritten records was observed in $96.3 \%, 71.4 \%$, and $97.9 \%$ of trainees, attending anesthesiologists, and nurses, respectively. Although almost all participants in our study highly recommended the AIMS over manual documentation for accurate data entry of vital signs and usefulness in data research, AIMS was not considered as being superior to handwritten records for managing malpractice risk by many attending anesthesiologist and trainees. This could be ascribed to the lack of experience in malpractice litigations with AIMS in those involved in this survey. However, in contrast to our study when the participants showed rather negative to neutral attitudes toward legal issues, some suggested its potential positive role in this field. Cook et al. [3] reported that extreme readings of vital signs were absent in handwritten records compared to automated records. Reich et al. [4] also showed the 'phenomenon of smoothing' in handwritten anesthetic records, partly related to the resistance to reporting extremes and rapid changes in values. Indeed, handwritten records will always arouse suspicion during an unexpected event, while AIMS could provide an opposite effect. The accurate record keeping of AIMS was reported to be favored for legal defense by providing reliable, detailed, and legible records of actual events, and proving the appropriateness of the anesthetic act undertaken [5].

In addition, some other relevant deficits of AIMS were also mentioned in our survey. Our questionnaire sheet was designed to compare the subjective feeling among different types of surgeries, according to previous studies $[1,2,6,9]$. Compared to lengthy surgeries which lasted $>30 \mathrm{~min}$, and complicated cases which have more anesthetic concerns, subjective feelings of dissatisfaction with use of AIMS during short duration and simple surgeries were demonstrated in the current survey. Short surgery cases were defined as those which lasted $<30 \mathrm{~min}$, and simple surgeries were those with less concern related to anesthetic management without invasive monitoring and intervention, as in relatively healthy patients. User satisfaction with implementation of AIMS was also relatively lower during an urgent care state such as CPR. Especially, the lower satisfaction of the trainees was related to the inability to make pre-written notes to save time or carry the anesthesia worksheets. In high turn-over ORs where numerous anesthetic cases are performed, manually prewritten forms of anesthetic recordings may save time, (10 to 20 minutes long) by just filling in the details and signing off. This is not the case in AIMS, where one PC is fixed for each OR, and the anesthetic recording can be started only after the patient enters the room. In addition, complaints related to its inconvenience in CPR may be related to the unfamiliarity of the personnel with the use of the AIMS device. He or she has to spend time to go all through the hierarchic menu to find drugs or procedure notes 
that are not commonly used, and barcode checking of the numerous transfusion products, which were formerly left over for retrospective clearance in the era of manual recording, must be organized in advance. Another problem found was when transporting the patient to the post anesthesia care unit (PACU), where they have to re-log-in to the PACU computer and enter the last vital sign measurements, which definitely takes more time than to just jot down on the paper sheet. The inappropriate placement of hardware in the OR was also suggested. The mentioned problems may be cumbersome but not serious, and the level of dissatisfaction is actually improving with users' adjustment with the system. These subjective feelings of inconvenience may improve with time and more use of the system.

Interestingly, significant inter-group differences were observed in the current study. All of the trainees and nurses agreed on the usefulness of AIMS for time-saving, while only $71.4 \%$ of the attending anesthesiologists agreed. In regard to the duration and complexity of surgery, fewer trainees than nurses thought AIMS was better than hand-written records in short cases, and fewer attending anesthesiologists than nurses considered AIMS superior to hand-written records in lengthy or complicated cases. The attending anesthesiologists also considered AIMS better suited for anesthetic work performance compared to the hand-written record, although less frequently than nurses. The overall preference for the electronic record after 1 year routine use of AIMS seemed to be higher in groups of trainees and nurses compared to the attending anesthesiologists group, and differences were statistically significant $(\mathrm{P}=0.002$ and $\mathrm{P}=0.029$, respectively). Not surprisingly, the differences observed among the groups may be due to the fact that anesthetic data entry using a manual recording system was conducted by the trainees or nurses under the supervision of attending anesthesiologists in the OR. The attending anesthesiologists supervise record keeping rather than keeping it themselves, and thus may benefit the least from the change in the method of record keeping, while trainees are the ones who do most of the record keeping in the most troublesome anesthetic cases, and thus feel AIMS is better than manual recording because it reduces their work. In addition, we also observed that the trainees group showed the fastest adaptation to the proper use of AIMS, and this may be explained again by that fact that this group has the greatest opportunity to use and adopt the method.

In conclusion, after 1 year of routine use, this structured user survey revealed that the computerized anesthetic recording system was perceived by users as being a useful system in anesthesia.

\section{References}

1. Quinzio L, Junger A, Gottwald B, Benson M, Hartmann B, Jost A, et al. User acceptance of an anesthesia information management system. Eur J Anaesthesiol 2003; 20: 967-72.

2. Eden A, Grach M, Goldik Z, Shnaider I, Lazarovici H, BarnettGriness $\mathrm{O}$, et al. The implementation of an anesthesia information management system. Eur J Anaesthesiol 2006; 23: 882-9.

3. Cook RI, McDonald JS, Nunziata E. Differences between handwritten and automatic blood pressure records. Anesthesiology 1989; 71: 385-90.

4. Reich DL, Wood RK Jr, Mattar R, Krol M, Adams DC, Hossain S, et al. Arterial blood pressure and heart rate discrepancies between handwritten and computerized anesthesia records. Anesth Analg 2000; 91: 612-6.

5. Feldman JM. Do anesthesia information systems increase malpractice exposure? Results of a survey. Anesth Analg 2004; 99: 840-3.

6. Beilin Y, Wax D, Torrillo T, Mungall D, Guinn N, Henriquez J, et al. A survey of anesthesiololgists' and nurses' attitudes toward the implementation of an Anesthesia Information Mangement System on a labor and delivery floor. Int J Obstet Anesth 2009; 18: 22-7.

7. Benson M, Junger A, Fuchs C, Quinzio L, Böttger S, Jost A, et al. Using an anesthesia information management system to prove a deficit in voluntary reporting of adverse events in a quality assurance program. J Clin Monit Comput 2000; 16: 211-7.

8. Lubarsky DA, Sanderson IC, Gilbert WC, King KP, Ginsberg B, Dear GL, et al. Using an anesthesia information management system as a cost containment tool. Anesthesiology 1997; 86: 1161-9.

9. Coleman RL, Stanley T 3rd, Gilbert WC, Sanderson IC, Moyer GA, Sibert KS, et al. The implementation and acceptance of an intraoperative anesthesia information management system. J Clin Monit 1997; 13: 121-8.

10. Edsall DW, Deshane P, Giles C, Dick D, Sloan B, Farrow J. Computerized patient anesthesia records: less time and better quality than manually produced anesthesia records. J Clin Anesth 1993; 5: 275-83.

11. Junger A, Hartmann B, Benson M, Schindler E, Dietrich G, Jost A, et al. The use of an anesthesia information management system for prediction of antiemetic rescue treatment at the postanesthesia care unit. Anesth Analg 2001; 92: 1203-9.

12. Jost A, Junger A, Zickmann B, Hartmann B, Banzhaf A, Quinzio L, et al. Potential benefits of Anaesthesia Information Management Systems for multicentre data evaluation: risk calculation of inotropic support in patients undergoing cardiac surgery. Med Inform Internet Med 2003; 28: 7-19.

13. O’Reilly M, Talsma A, VanRiper S, Kheterpal S, Burney R. An anesthesia information system designed to provide physicianspecific feedback improves timely administration of prophylactic antibiotics. Anesth Analg 2006; 103: 908-12.

14. Allard J, Dzwonczyk D, Yablok F, Block FE Jr, McDonald JS. Effect of automatic record keeping on vigilance and record keeping time. $\mathrm{Br}$ J Anaesth 1995; 74: 619-26. 